\title{
Selection and Application of Materials in Chemical Machinery Design
}

\author{
Ziyi Xiao ${ }^{1, *}$, Zhongfa $\mathrm{Du}^{2}$, Zhejun Huang ${ }^{3}$,Anyang Tang ${ }^{4}$ \\ ${ }^{1}$ Nanchang University,Nanchang Jiangxi PRC \\ ${ }^{2}$ Shandong Jiaotong University, Weihai Shandong,PRC \\ ${ }^{3}$ Wuhan Institute of Design and Engineering, Wuhan Hubei,PRC \\ ${ }^{4}$ Chongqing university city institute of science and technology,Chongqing.PRC
}

\begin{abstract}
Materials used in the design of chemical machinery are an indispensable part of industrial production, and chemical machinery materials are also the main basis of chemical production.Chemical mechanical properties can directly determine the quality of products in chemical production, and their materials also determine the quality of chemical mechanical properties. Selecting corresponding materials has become the core of chemical mechanical design.Therefore, in the design of chemical machinery, there is a special value for the selection of materials used in manufacturing.
\end{abstract}

\section{INTRODUCTION}

With the continuous growth of national economy, the pr oduction of chemical industry has entered a new develop ment period. New methods and technologies overlap one another, resulting in large-scale development and produ ction of chemical industry, which adds many material we alth to the development and life of national society and a ccelerates the pace of social development.In the design o f chemical machinery, it is very important to select suita ble materials.Improving such chemical industry can not only improve the comprehensive economic effect and $\mathrm{pr}$ omote the continuous development of society, but also ef fectively promote the development of chemical producti on and improve the working efficiency of equipment.

\section{Main Functions of Material Selection and Operation in Chemical Machinery Equipment}

With the rapid development of national market economy, construction in various fields is at the peak of continuou $\mathrm{s}$ development, and the demand for chemical products is also increasing gradually. Therefore, chemical machiner $\mathrm{y}$ and equipment are greatly developed.However, due to $\mathrm{t}$ he increasing demand for materials in various fields, the supply of materials used in chemical machinery design is in short supply, and the shortage of mechanical material $\mathrm{s}$ becomes more and more serious.Based on the new era, the selection of suitable mechanical materials can not onl y ensure the mechanical quality and performance, but als o make the operation of equipment more humanized and safe, such as excellent materials can effectively reduce $n$ oise and reduce hazards to human body [1].In addition, we should not only consider the quality of mechanical $\mathrm{m}$ aterials in front of us, but also select the mechanical mat erials with environmental protection, energy saving, sust ainable development and economy, and reasonably use $\mathrm{t}$ he limited resources to expand the chemical field. This is the only way for the sustainable development of chemic al industry and also the only feasible way.

\section{Accounting internal control strategy based on financial management of enterprises}

\subsection{Selection of common steel materials}

Based on the background of chemical mechanical design, steel is one of the most commonly used mechanical mat erials.Common steel materials are usually of two types: a lloy steel and carbon steel.Carbon steel is chemically pro cessed and its mechanical parts are relatively stable. Mos $t$ of them are used in the processing of some parts.In addi tion, due to the current steel price restriction, the price of carbon steel in China is relatively low. Using carbon ste el as processing material can effectively reduce company costs.However, due to the high carbon content in carbon steel, the toughness is relatively reduced under high stre ngth conditions.For some relatively large parts, the actua 1 force is quite large. Poor flexibility will cause damage $t$ o the parts, so it does not conform to the parts with large processing volume.Alloy steel is a new type of steel base $\mathrm{d}$ on the combination of carbon steel and other metals. A lloy steel can not only retain the advantage of high streng th of carbon steel, but also provide better toughness for $n$ ewly added metals [2].Therefore, the appearance of alloy steel provides a new material selection for the field of $\mathrm{m}$ achining.

\footnotetext{
*orresponding author: author@e-mail.org
} 


\subsection{Material recycling}

According to the national vigorously advocating to build a resource-saving society, in view of the progress in the $f$ ield of technology and under the annual limit of products, obsolete equipment should be eliminated for waste recy cling and reuse, which attracts much attention.Metal is $u$ sually used as comprehensive material for chemical mac hinery design.However, there are more than 100 kinds of metal materials available for material processing industr $\mathrm{y}$ in today's society.If the selection of metal types for che mical equipment is too tedious, it will bring a certain stre ngth to the classification of metal materials when recycli ng and reusing.Therefore, it is strongly required to follo $\mathrm{w}$ the single principle as far as possible in the selection o $\mathrm{f}$ materials in the design of chemical machinery, to select a single alloy as possible, and to facilitate the implement ation of recycling, classification and integration, and to $\mathrm{i}$ mplement the recycling and utilization of old equipment.

\subsection{Selection of suitable materials according to production process}

In the design of chemical machinery, first of all, consider ation should be given to the different manufacturing proc esses of parts when they are manufactured.When materia 1 processing is carried out for the designed chemical mec hanical equipment, the main manufacturing processes ar e welding, casting, cutting, etc.The requirements for mat erials used vary according to the manufacturing process. For example, when cutting a material, one should think a bout whether the material used is good for cutting, wheth er the material used is easy to cast, and whether the mate rial used has excessive compressive resistance when wel ding.Therefore, the materials used should be selected ap propriately according to the production process and mate rial characteristics.

\subsection{Bearing material}

In the production of chemical machinery, chemical equip ment will generally face two situations: first, when the e quipment is running, some parts of the equipment will be ar a lot of force. The stress condition will cause parts to $\mathrm{w}$ ear to varying degrees until deformation, resulting in sho rter service life of the equipment.Therefore, the toughnes $\mathrm{s}$ and wear resistance of materials should be considered $\mathrm{f}$ or the parts which are heavily stressed in actual producti on. It is expected that such parts should be processed by $\mathrm{i}$ nfiltrating carbon into low carbon steel using materials $\mathrm{w}$ ith high toughness and strength.Secondly, for some equi pments with equal force, the force generated in the specif ic production will be applied to such parts on average. W hether stretching or extrusion, parts can maintain force $b$ alance, so it is impossible for a part to wear at a faster sp eed [3].For example, all parts of automobile structure are balanced in material and stress structure, and the materia ls used also have good bearing capacity, as shown in Fig ure 1.

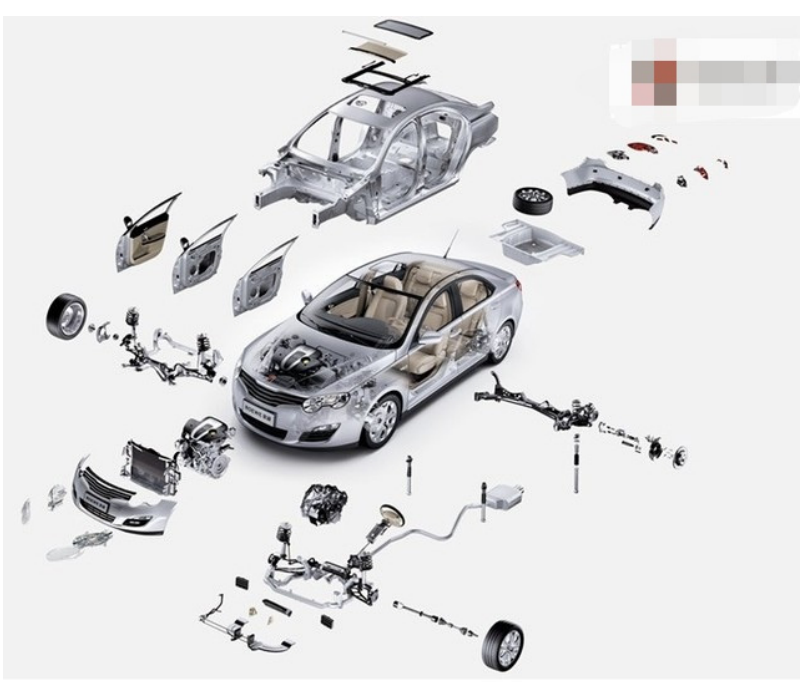

Fig. 1. Structural performance diagram of parts used in automobile mechanical equipment

\section{Specific Analysis of Material Applicati on in Chemical Machinery Design}

The application of materials in chemical mechanical desi gn is an extension and presentation of high and low quali ty of material selection and plays a crucial role in compr ehensive mechanical design.In the design of chemical $\mathrm{m}$ achinery, the scientific nature of material selection is par ticularly important.At the same time, the energy-saving, environmental protection and economy of material appli cation are also particularly worthy of close attention of c hemical machinery workers.In other words, how to effec tively handle the unity of operability, energy saving, envi ronmental protection and economy in material applicatio $\mathrm{n}$ on the basis of quality of material selection has already become the core topic of mechanical design work, and a lso the sudden trend of sustainable development in proce ssing field and mechanical production field.

\subsection{Ensure energy-saving and environmental protection in the application of mechanical design materials}

Material selection and application in chemical machinery design need to be combined with energy saving and envi ronmental protection. At the same time, it should be give $\mathrm{n}$ a new requirement in the field of mechanical design as a long-term development concept in the construction and development of Eco-economy and society, which should arouse great concern of relevant workers.In the develop ment of social market economy, the consumption and re quirements of various non-renewable materials will defin itely leave hidden dangers for the application and selecti on of chemical machinery design materials. Therefore, th e integration of environmental protection and energy sav ing in material application has become the core of curren t machining work.For example, in the work of mechanic al design castings, taking material application as an exa mple, the cost of $4.5 \%$ in the process of casting design $d$ etermines about $75 \%$ of the production cost of castings [4].This reminds us to attach importance to energy-savin 
$\mathrm{g}$ and environmental protection in the application of mat erials in mechanical design, which can not only reduce $u$ nnecessary energy consumption costs, but also save costs and raw materials effectively. In addition, the broad spa ce for innovation can also meet the environmental requir ements in the application process of materials in mechani cal design.

\subsection{Ensure that mechanical material parts are guided by manufacturing process}

In chemical machining and production, cutting, welding, casting and heat treatment require different application o $\mathrm{f}$ mechanical design materials in processing technology [5].Careful analysis shows that the cutting process needs to be in accordance with the advantages of cutting operat ion in the application of mechanical design materials; the casting process strives to develop in the direction of hig $\mathrm{h}$ fluidity and high shrinkage in the application of mecha nical design materials. The welding process should consi der comprehensively the cold pier property and stamping property of the material in its material transportation an $\mathrm{d}$ application. The heat treatment process should confor $\mathrm{m}$ to the main properties of oxidation decarbonization, $\mathrm{h}$ ardenability and superheat sensitivity in the application o f mechanical design material.

\subsection{The application of mechanical design materials should be controlled economically}

In the design of chemical machinery, great attention sho uld be paid to the market economy at that time in the app lication of materials. The analysis shows that in the appli cation of chemical machinery design materials, the perfo rmance of parts and materials system should be guarante ed to meet the foundation, and the process cost of materi als and parts should be scientifically controlled.Therefor $\mathrm{e}$, it is necessary to organically integrate chemical units with existing production conditions of mechanical produ ction and to reasonably control the processing technolog $\mathrm{y}$ and casting-forming route of mechanical parts.

\section{Measures to Improve Material Selectio $\mathbf{n}$ and Operation in Chemical Machinery Equipment Design}

\subsection{Improving corrosion protection design}

In the design of chemical machinery, mechanical equipm ent usually processes some corrosive products, such as c hlorine, fertilizer, alcohol and so on. At this time, the cor rosion resistance of chemical machinery equipment is pa rticularly important.In order to effectively prevent chemi cal machinery from being corroded, we need to use corro sion-resistant materials [6] at the beginning of the design. But in addition, adequate protective measures should be $\mathrm{t}$ aken in the specific application process to centralize corr osive articles in one place so as to avoid close contact wi th mechanical equipment and thus cause different degree $\mathrm{s}$ of harm to mechanical equipment.

\subsection{Perfect Selection of Alloy Steel and Carbon Steel for Chemical Equipment}

Before making the material selection for chemical equip ment, it is necessary to know the working environment a nd performance of chemical equipment and choose the a ppropriate material to meet the requirements of effective production.During the design, not only the practicability, safety and non-toxicity of materials must be guaranteed, but also the chemical and physical properties of material s must be considered comprehensively.For example, allo yed steels can be made by injecting trace alloying eleme nts into carbon steels, which have a particularly high perf ormance and are easy to obtain, and are also suitable for use in places with high wear, high temperature and stron g corrosiveness.Alloy steel has many special properties, but it can not completely replace carbon steel, because ca rbon steel has its own unique advantages and characterist ics [8].Therefore, in the selection, it must be selected acc ording to the actual requirements of chemical machinery and equipment.Only in this way can the use efficiency of materials be maximized.

\subsection{Material selection shall be based on the manufacturing process of mechanical parts}

Chemical mechanical equipment is also from mechanical processing, so the selection of material for chemical me chanical equipment must have Machinable characteristic s.In view of the different requirements of materials for $\mathrm{v}$ arious processes, in the process of chemical machinery e quipment design, the selection of materials for machiner $y$ must be carried out according to the requirements of di fferent parts processing processes, not only focusing on $t$ he feasibility of specific processing, but also on the scien tificity of design.After ensuring the economic use of mat erials, we should also consider the pass rate of finished $p$ roducts of machine materials in the process of processing. Some materials need to be processed several times befor e they can be produced as a good product, which undoub tedly increases the production cost and wastes a lot of ti me [9].Commonality and standard parts should be used a $\mathrm{s}$ much as possible in the design of chemical machinery $\mathrm{t}$ o simplify the design process and thus effectively reduce costs and input standards.

\section{Conclusion}

In the field of chemical machinery design, material selec tion has always been one of the topics of great concern $i$ $\mathrm{n}$ the field of chemical production.At the same time, in o rder to make the production work in chemical industry $\mathrm{m}$ ore stable and internationalized, scientific researchers in chemical production field are gradually deepening the re search and development of chemical machinery and equi pment.Only by properly selecting chemical machinery $\mathrm{m}$ aterials can chemical groups produce chemical products with high efficiency and durability, and improve the basi c work of chemical production, can chemical groups ens ure that the products produced by chemical production $n$ ot only have high efficiency but also have better quality, 
thus promoting domestic technology in chemical product ion to all parts of the world.

\section{References}

1. Zhang Fuji.Discussion on Material Selection in Chemical Machinery Design [J]. Architectural Engineering Technology and Design, 2019 (13): 693.

2. Zhang Jian.Material Selection and Application Research in Chemical Machinery Design [J].Tianjin Chemical Industry, 2019.33(1): 51-52.

3. Jing Xiaoning, Li Hui. Material Selection and Application Research in Chemical Machinery Design [J]. Global Market, 2019 (6): 360.

4. Zhang Zhenguo, Zhang Na. On Material Selection in Chemical Machinery Design [J]. China Chemical Trade, 2018.10 (31): 20.

5. Xiao Miaomiao. Discussion on Material Selection in Chemical Machinery Design [J]. China Chemical Trade, 2018.10 (29): 21,23.

6. Sun Hongmei. On Material Selection in Chemical Machinery Design [J]. Chemical Industry Management, 2018 (22): 152-153.

7. Li Xiuxiu.Discussion on Material Selection and Application in Chemical Machinery Design [J]. Decorative Decoration Tiandi, 2018 (2): 181.

8. Xu Ronggang, Xiao Jinjian. On Material Selection and Application in Chemical Machinery Design [J]. Chemical Management, 2017 (24): 204.

9. Huigang. Discussion on Material Selection in Chemical Machinery Design [J]. SME Management and Technology, 2017 (10): 139-140. 